\title{
Radical Chain Monoalkylation of Pyridines
}

\author{
Samuel Rieder, ${ }^{{ }^{\dagger}}$ Camilo Meléndez, ${ }^{{ }^{\dagger}}$ Kleni Mulliri $^{\mathrm{a}}$ and Philippe Renaud ${ }^{\mathrm{a}}$ \\ The monoalkylation of $\mathrm{N}$-methoxypyridinium salts with alkyl radicals generated from alkenes (via hydroboration with \\ catecholborane), alkyl iodides (via iodine atom transfer) and xanthates is reported. The reaction proceeds under neutral \\ conditions since no acid is needed to activate the heterocycle and does not require the use of an external oxidant. A rate \\ constant for the addition of a primary radical to $N$-methoxylepidinium $>10^{7} \mathrm{M}^{-1} \mathrm{~s}^{-1}$ was experimentally determined. This rate \\ constant is more than one order of magnitude larger than the one measured for the addition of primary alkyl radical to \\ protonated lepidine demonstrating the remarkable reactivity of methoxypyridinium salts towards radicals. The reaction \\ could be extended to a three component carbopyridinylation of electron rich alkenes including enol esters, enol ethers and \\ enamides.
}

\section{Introduction}

Aromatic heterocyclic compounds, especially nitrogen containing rings, are core elements of vitamins, amino acids, nucleic acids, and alkaloids and thus attract the attention of the synthetic community and the pharmaceutical industry since many years. ${ }^{1}$ A recent study has shown that $59 \%$ of U.S. FDA approved small-molecule drugs contain a nitrogen heterocycles. ${ }^{2}$ Their late-stage functionalization is of great interest to modify and tune their pharmaceutical properties. For instance, introduction of carbon substituents under mild conditions holds great potential and remains a privileged goal. ${ }^{3}$ Homolytic aromatic substitution reactions $\left(\mathrm{S}_{H} \mathrm{Ar}\right)$ is a longknown reaction and early examples date back to over a century ago. 4,5 The Minisci reaction, which involves the addition of a nucleophilic carbon-centered alkyl- or acyl radical onto a protonated heteroaromatic compound, is of particular importance due to its broad scope. 6,7 The classical method uses alkyl- and acyl radicals generated by hydrogen atom abstraction with persulfate and a silver(I) salt. ${ }^{6,8}$ During the past years, many variations of this transformations have been reported with different sources of alkyl radicals such as alkyl trifluoroborates ${ }^{9,10}$, boronic acids ${ }^{11,12}$ alcohols, ${ }^{13}$ zinc sulfinates $^{14,15} \mathrm{~N}$-(acyloxy)-phthalimides, ${ }^{16}$ simple alkanes and ethers ${ }^{17-20}$ to name some of the leading work. Despite their efficacy, $\mathrm{S}_{H} \mathrm{Ar}$ reactions suffer from some limitations such as regioselectivity control and polyalkylation. Furthermore, all the above-mentioned examples involve a rearomatization process via single-electron oxidation using either a stoichiometric oxidant or photoredox catalysis. Non-acidic activation of pyridine derivative has also been reported. For instance, the use of pyridine- $\mathrm{N}$-oxides, ${ }^{21,22} \mathrm{~N}$-iminopyridine ylides, ${ }^{18}$ and $\mathrm{N}$ methoxypyridinium salts ${ }^{23-27}$ have been examined. The two last substrates are potentially particularly interesting since the aromatization step does not require any external oxidant and the reaction affords simple pyridines that do not react further with radicals. In a pioneer work, Mitchell and co-workers have developed a Minisci-type procedure for the hydroxymethylation of pyridines involving involving $\mathrm{N}$ methoxypyridinium derivatives (Scheme 1A). ${ }^{23}$ Three different mechanisms where proposed for the rearomatization step, among them the one involving the fragmentation of a methoxyl radical that sustain a chain process via hydrogen atom abstraction from methanol was the most plausible. The role of the oxidant (ammonium persulfate) used in substoichiometric amount is to initiate the reaction. The scope of this reaction was limited to methanol and ethanol (one example) used as solvent, but this study nicely demonstrated the usefulness of methoxypyridinium salts to perform monoalkylation of pyridines derivatives. This work was extended by Baik, Hong and co-workers who developed a site selective photocatalyzed functionalization of $\mathrm{N}$-methoxypyridnium salts with phosphinoyl and carbamoyl radicals (Scheme 1B).28,29 In analogy to Mitchell's chemistry, the desired alkyl radicals were generated by a hydrogen atom abstraction step. Very recently, a related process for alkylation under mild basic conditions of $\mathrm{N}$-methoxylepidinium salts was reported by Shen et al. ${ }^{30}$ Herzon and co-workers extended considerably the scope of Mitchell reaction to secondary and tertiary alkyl radicals generated from alkenes under cobalt mediated hydrogen atom transfer conditions and to a broad range of heterocycles such as pyridine, imidazole and pyridazine (Scheme 1C). ${ }^{26,27}$ This reaction require a stoichiometric amount of cobalt which and it was proposed that aromatization took place via reduction of the intermediate radical cation by a Co(II) species followed by methanol elimination. Interestingly, the reaction could be extended to a borono-Minisci reaction under oxidative conditions (potassium persulfate and silver(I)). In a related manner, three component coupling reactions involving $\mathrm{N}$ methoxypyridinium salts were developed by Baik, Hong and coworkers ${ }^{31}$ using a $\mathrm{Mn}(\mathrm{III}) / \mathrm{Ag}(\mathrm{I})$ oxidizing system and by Nagib and co-workers using an iridium based photocatalyst. ${ }^{32,33}$ 


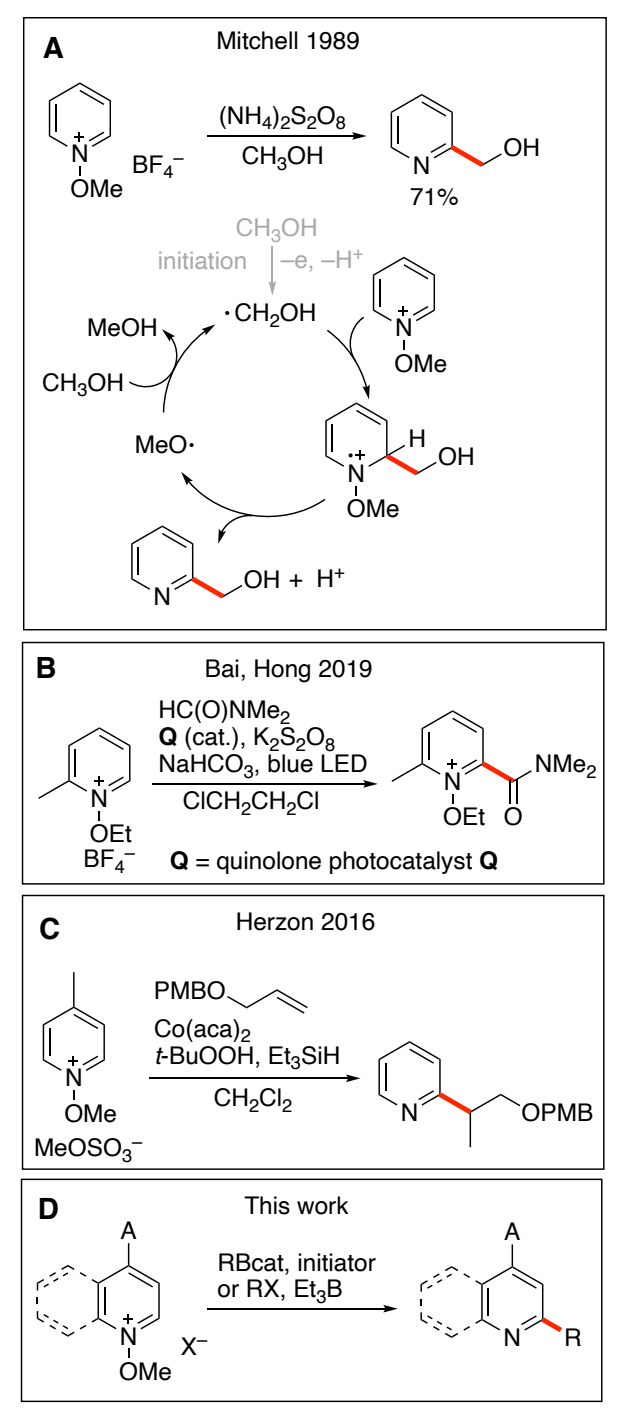

Scheme 1. Radical addition to $N$-alkoxypyridinium salts.

Based on these precedents, we hypothesized that the methoxyl radical proposed in Mitchell's mechanism could be used to sustain a radical chain process involving organobranes. We report here a general method for a radical mediated monoalkylation of pyridines and related heterocycles using easily available $B$-alkylcatecholboranes (RBcat), alkyl iodides, and xanthates under radical chain reaction conditions without the need of any stoichiometric oxidant (Scheme 1D).

\section{Results and Discussion}

a) Reaction with organoboranes generated via hydroboration of alkenes.

\section{Optimization}

We initially examined the alkylation of 1-methoxy-4phenylpyridinium tetrafluoroborate $\left(\mathbf{1} a \cdot \mathrm{BF}_{4}\right)$ with 2cyclohexylbenzo- $[d][1,3,2]$ dioxaborole (CyBcat) as a model system. ${ }^{34}$ Methoxypyridium salt $\mathbf{1 a} \cdot \mathrm{BF}_{4}$ was prepared by oxidation of 4-phenylpyridine with $m$-CPBA followed by methylation with the Meerwein's salt $\left(\mathrm{Me}_{3} \mathrm{OBF}_{4}\right) \cdot{ }^{35} \mathrm{CyBcat}$ was prepared in situ by hydroboration of cyclohexene with catecholborane (catBH) and $\mathrm{N}, \mathrm{N}$-dimethylacetamide (DMA) as a catalyst. ${ }^{36}$ The reaction were performed with di-tert-butylhyponitrite $(\mathrm{DTBHN})^{37}$ as a radical initiator. Optimization experiments are summarized in Table 1.

Table 1 Optimizing conditions for the alkylation of $\mathrm{N}$-methoxy pyrididinium 1 with CyBcat.

\begin{tabular}{|c|c|c|c|c|c|}
\hline $1 \mathrm{OM} \cdot \mathrm{BF}_{4}$ & \multicolumn{2}{|c|}{$\begin{array}{l}\text { CyBcat } \\
\text { DTBHN (10 mol\%) } \\
\text { 2,4,6-collidine } \\
\text { solvent, } 40^{\circ} \mathrm{C}, 18 \mathrm{~h}\end{array}$} & $\mathrm{Ph}$ & $\mathrm{Ph}$ & \\
\hline \multirow[t]{2}{*}{ Entry $^{a}$} & \multirow[t]{2}{*}{ Solvent } & \multirow{2}{*}{$\begin{array}{l}\text { CyBcat } \\
\text { (equiv) }\end{array}$} & \multirow{2}{*}{$\begin{array}{c}\text { 2,4,6-collidine } \\
\text { (equiv) }\end{array}$} & \multicolumn{2}{|c|}{ Yield $^{b}$} \\
\hline & & & & 2 & $2^{\prime}$ \\
\hline 1 & $\mathrm{CH}_{2} \mathrm{Cl}_{2}$ & 3.0 & - & $36 \%^{c}$ & $14 \%^{c}$ \\
\hline 2 & $\mathrm{CH}_{2} \mathrm{Cl}_{2}$ & 3.0 & 5 & $46 \%$ & - \\
\hline 3 & $\mathrm{CH}_{2} \mathrm{Cl}_{2}$ & 1.5 & - & $55 \%$ & $5 \%$ \\
\hline 4 & $\mathrm{CH}_{2} \mathrm{Cl}_{2}$ & 1.5 & 3 & $54 \%$ & $8 \%$ \\
\hline 5 & EtOAc & 1.5 & - & $45 \%^{c}$ & $17 \%$ \\
\hline 6 & $\mathrm{C}_{6} \mathrm{H}_{6}$ & 1.5 & - & $10 \%$ & - \\
\hline 7 & DCE & 1.5 & - & $63 \%$ & $5 \%$ \\
\hline 8 & DCE & 1.5 & 3 & $63 \%^{c}$ & - \\
\hline 9 & DCE & 1.5 & - & $55 \%^{d}$ & $4 \%$ \\
\hline 10 & DCE & 1.5 & - & $28 \%$ e & $2 \%$ \\
\hline
\end{tabular}

a) Reagents and conditions (entries $3,5-7: 1 \cdot \mathrm{BF}_{4}(1 \mathrm{mmol})$, alkene (1.5 equiv.), catecholborane (3.0 equiv.), DMA (0.32 mol\%), DTBHN (10 mol\%), solvent $(10 \mathrm{~mL}), 40^{\circ} \mathrm{C}, 18 \mathrm{~h}$. b) Yields are determined by GC unless otherwise stated. c) Isolated yield. d) Air as initiator instead of DTBHN. e) No added initiator.

In dichloromethane and in the absence of any additive, the desired mono-alkylated product 2 was obtained in 36\% yield along with $14 \%$ of the disubstituted product 2'. The formation of the bisalkylated product was not expected and attributed to acidic activation of pyridine $\mathbf{2}$ by the acid formed during the rearomatization process (one proton is eliminated together with the methoxyl radical). The bis-alkylation could be suppressed by adding 2,4,6-trimethylpyridine (sym.-collidine, 5 equiv) as base (Table 1 , entry 2 ). Slightly higher yields were obtained by using a smaller excess ( 1.5 equivalents) of CyBcat in the presence or not of sym.-collidine (Table 1, entires 3 and 4). Different solvents were tested then. Ethyl acetate (EtOAc) and benzene proved to be less efficient than dichloromethane (Table 1, entries 5 and 6) due to limited solubility of the methoxypyridinium $1 \mathrm{a} \cdot \mathrm{BF}_{4}$ in these solvents. The use if $1,2-$ dichloroethane (DCE) allow to fully solubilize $1 \mathrm{a} \cdot \mathrm{BF}_{4}$ at $40{ }^{\circ} \mathrm{C}$ and the reaction afforded $\mathbf{2}$ in $63 \%$ yield with $5 \%$ of the dialkylated pyridine 2' (Table 1, entry 7). Changing the counter-anion from tetrafluoroborate $\left(\mathrm{BF}_{4}^{-}\right)$of 1 a to hexafluorophosphate $\left(\mathrm{PF}_{6}{ }^{-}\right)$ increased solubility of the substrate but it had no influence on the outcome of the reaction. When the reaction was run in DCE with 2,4,6-collidine as an additive (3 equiv), the reaction afforded exclusively $\mathbf{2}$ in 63\% isolated yield (Table 1, entry 8). The reaction was also run using air initiation (open system) leading to a slight decrease of the yield (55\%, Table 1, entry 9). In the absence of any added initiator, traces of oxygen are 
sufficient to trigger the formation of $\mathbf{2}$ albeit in lower yield (28\%, Table 1, entry 10) suggesting that an efficient chain process is taking place.

Since pyridine derivatives are challenging to purify, the reaction was further optimized with lepidine (Table 2). Reaction of $N$ methoxylepidinium $\mathbf{1 b} \cdot \mathrm{BF}_{4}$ substrate furnished the alkylated lepidine 3 in 93\% yield (GC analysis) (Table 2, entry 1). In this reaction, the use of 2,4,6-collidine was not necessary since no di- or polyalkylation was observed and the yield remains identical in the absence of collidine (Table 2, entry 2). An experiment with air initiation (open reaction vessel) gave the product in $95 \%$ yield (Table 2 , entry 3 ). To guarantee an optimal reproducibility, all reactions were performed with DTBHN, air initiation being more influenced by the exact experimental setup. The nature of the alkoxy group (methoxy vs. ethoxy) was tested then (Table 2, entry 4 ) and did not affect the outcome of the reaction. Product isolation is often problematic with pyridines derivatives. Best results were obtained by filtration of the crude mixture through basic aluminum oxide to remove residual acid impurities and catechol byproducts followed by column chromatography without pressure using $12 \mathrm{~g}$ silica gel per mmol of starting pyridinium salt. With this method, the isolated yield closely matched the yield determined by GC analysis (Table 2 , entry 5).

Table 2. Final optimization of the reaction with $N$-methoxylepidinium $\mathbf{1 b}$-BF4.

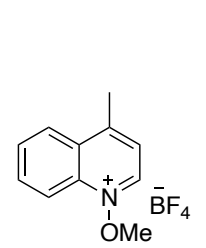

1b. $\mathrm{BF}_{4}$

\begin{tabular}{cccc}
\hline Entry & initiator & collidine & Yield 3 \\
\hline 1 & DTBHN & 3 equiv & $93 \%(G C)$ \\
2 & DTBHN & - & $93 \%(G C)$ \\
3 & air & - & $95 \%(G C)$ \\
4 & DTBHN & - & $92 \%(G C)^{1}$ \\
5 & DTBHN & - & $85 \%$ (isolated) \\
\hline
\end{tabular}

1) Using the ethoxylepinidinium instead of the methoxylepinidinium salt.

\section{Reaction scope}

The optimized reaction conditions were tested with a series of quinolines and pyridines and several radical precursors. Results are summarized in Scheme 2. All reactions involving methoxyquinolinium ions were run without 2,4,6-collidine. Secondary cyclic radicals generated from cyclohexene and cyclododecene reacted with $\mathrm{N}$-methoxylepidinium $\mathbf{1 b}$ to give products 3 and $\mathbf{4}$ in high yields. Terminal alkenes such as 1hexene and 1-octene gave the alkylated products 5 and $\mathbf{6}$ in good yields. Since the hydroboration is not fully regioselective, small amounts of the branched isomers are also observed (6$11 \%)$. Performing the reaction with commercially available triethylborane as source of ethyl radical furnished product $\mathbf{7}$ in 79\% yield. Even the tertiary alkyl radical generated from tetramethylethylene, react efficiently with $\mathbf{1 b}$ and to afford $\mathbf{8}$ in
$80 \%$ yield. The diastereoselectivtiy of the process was investigated with 1-methylcyclohexene. The trans isomer of $\mathbf{9}$ was formed with an excellent sterocontrol (cis/trans $\geq 97: 3$ ). Both $\alpha$ - and $\beta$-pinene were also investigated and provided the alkylated lepidine $\mathbf{1 0}$ and $\mathbf{1 1}$ in high yields and excellent stereocontrol. ${ }^{38}$ Different $\mathrm{N}$-methoxyquinolinium salts such $\mathrm{N}$ methoxy-4-chloroquinolinium 1c, 5-methoxyphenanthridin-5ium 1d afforded upon reaction with cyclohexene the monoalkylated products 12 and 13 in $85 \%$ and $70 \%$ yield, respectively. Reaction of cyclohexene with 1-methoxy-3bromoquinolinium 1e gave product 14 in modest yield (38\%). NMethoxyquinaldinium If was not alkylated under the same reaction conditions. However, in the presence of 2,4,5-collidine (conditions A) the 4-cyclohexyquinaldine $\mathbf{1 5}$ was obtained in $38 \%$ yield together with a significant amount of the demethoxylated quinaldine. A marginally higher yield was obtained with the $N$-ethoxyquinaldinium salt 1f' (42\%). A possible pathways leading to the formation of the demethoxylated quinaldine involves deprotonation at the methyl position followed by a homolytic fragmentation of the $\mathrm{N}$-OMe bond according to the work of Shen et al. liberating a methoxyl radical and a benzylic radical that can abstract a hydrogen from the reaction mixture. ${ }^{30}$ Reactions with substituted $N$-methoxypyridinium salts were also investigated. For these substrates, the use of 2,4,6-collidine had a very positive effect on the outcome of the reactions (compare conditions A with 2,4,6-collidine and B without base). Reaction of 1a with cyclohexene, 1-dodecene and tetramethylethylene under conditions A afforded 2, 16 and $\mathbf{1 7}$ in modest to good yields. The 4-tert-butyl- and 4-ethoxycarbonyl-1methoxypyroidinium salts $\mathbf{1 g}$ and $\mathbf{1 h}$ were both monoalkylated with cyclohexene to afford 18 and 19 in 65 and $46 \%$ yield, respectively. 


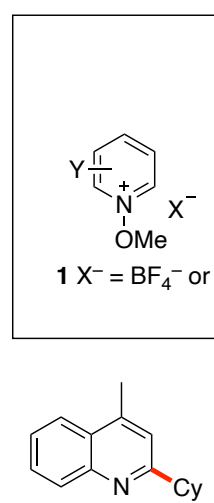

3 93\% (B)

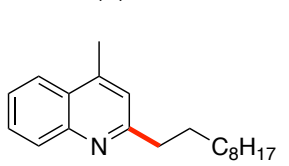

$675 \%$ (B)<smiles>Cc1cc([C@H]2CCCC[C@H]2C)nc2ccccc12</smiles>

$986 \%$ (B) trans/cis $\geq 97: 3^{c}$<smiles>Clc1cc(Cl)c2ccccc2n1</smiles>

$1285 \%$ (B)
1) alkene (1.5 equiv) CatBH (3.0 equiv)

$\mathrm{Me}_{2} \mathrm{NC}(\mathrm{O}) \mathrm{Me}(30 \mathrm{~mol} \%$ )

2) tert-butanol (1.8 equiv)

A or B

DCE, $45^{\circ} \mathrm{C}, 4-16 \mathrm{~h}$

A: $2,4,6$-collidine (3 equiv)

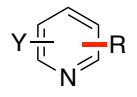

A: $2,4,6-$ collidine
B: no additive
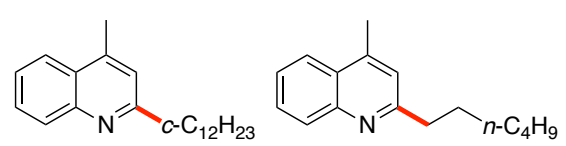

4 92\% (B)

$575 \%^{a}(B)$<smiles>CCc1cc(C)c2ccccc2n1</smiles>

$779 \%^{b}(B)$<smiles>Cc1cc(C(C)(C)C(C)C)nc2ccccc12</smiles>

$880 \%$ (B)<smiles>Cc1cc([C@H]2C[C@H]3C[C@@H](C2OC(=O)O)C3(C)C)nc2ccccc12</smiles>
$1086 \%$ (B) dr 99:1

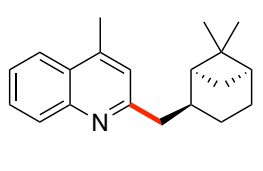

$1178 \%$ (B) dr 9:1 ${ }^{\mathrm{c}}$<smiles>c1ccc2c(c1)nc(C1CCCCC1)c1ccccc12</smiles>

$1370 \%(B)$<smiles>Clc1nc2ccccc2cc1Br</smiles>

$1438 \%(B)$<smiles>Cc1cc(Cl)c2ccccc2n1</smiles>

$1542 \%(A)$
DTBHN (10 mol\%)<smiles>c1ccc(-c2ccncc2)cc1</smiles>

$263 \%$ (A) $\leq 19 \%$ (B)<smiles>CCCCCOc1cc(-c2ccccc2)ccn1</smiles>

$1654 \%$ (A) $\leq 20 \%$ (B)

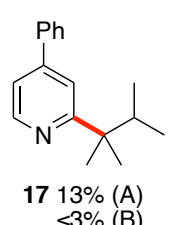

$$
\leq 3 \%(B)
$$<smiles>CC(C)(C)c1ccnc(Cl)c1</smiles><smiles>CCOC(=O)c1ccnc(Cl)c1</smiles>

$1865 \%(A)$
$27 \%(B)$

$1946 \%$ (A)

$13 \%(B)$
Scheme 2. Reaction of $N$-methoxylepidinium and $N$-methoxypyridinium salts 1 with radical generated from $B$-alkylcatecholboranes. a) Contains $11 \%$ of the branched 2-hexyl isomer. b) Reaction run with $\mathrm{Et}_{3} \mathrm{~B}$ (1.5 equiv); c) Diastereoselectivity determined by GC-analysis, only the major diastereoisomer is depicted. d) Unsing $N$-ethoxylepidinium tetrafluoroborate.

The radical nature of the reaction was unambiguously demonstrated by the cyclopropane ring opening process observed when (+)-2-carene $\mathrm{e}^{39,40}$ was used as a radical precursor. Reaction with $\mathbf{1 b}$ afforded the substituted lepidine 20 in 76\% yield and high stereoselectivity (Scheme 3).

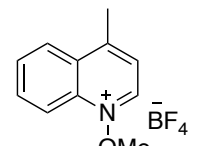
$\mathrm{OMe}$

$1 \mathrm{~b}$
1) (+)-2-carene ( 1.5 equiv) CatBH (3.0 equiv)

$\mathrm{Me}_{2} \mathrm{NC}(\mathrm{O}) \mathrm{Me}(30 \mathrm{~mol} \%)$

2) tert-butanol (1.8 equiv)

$\underset{\mathrm{DTBHN}}{\left.\mathrm{DCE}, 45^{\circ} \mathrm{C}, 30 \mathrm{~mol} \%\right)}$

DCE, $45^{\circ} \mathrm{C}, 30 \mathrm{~h}$

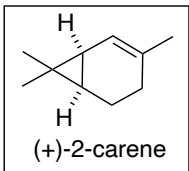

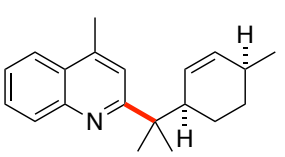

20 76\% (cis/trans 99:1)

\section{Mechanism}

The proposed mechanism for this reaction is depicted in Scheme 4. The chain is initiated by the thermal decomposition of DTBHN resulting in a tert-butoxyl radical that reacts with RBcat to produce the initial alkyl radical. ${ }^{34,41,42}$ Similarly, oxygen can initiate the reaction by reacting with the RBcat. Addition of the radical to the $\mathrm{N}$-methoxypyridinium affords a radical cation intermediate. Depending on the nature of the alkyl radical and of the trap, this step may be a reversible process (see results involving alkyl iodides in Scheme 6) Rearomatization takes place by loss of a proton followed by rapid elimination of a methoxyl radical that propagates the chain reaction. ${ }^{43}$ The rearomatization presumably involves the formation of an intermediate $\alpha$-amino radical. Similar intermediates are produced during the photoinduced demethoxylation of $\mathrm{N}$ methoxypyridinium salts. ${ }^{44-46} 2,4,6$-Collidine is expected to facilitate the rearomatization step and revoke the reversibility of the radical addition step. A related effect of a base has been recently reported by Shirakawa. ${ }^{47,48}$ This effect may explain why the more stabilized tertiary alkyl radicals reacts better in the presence of the base with the methoxypyridinium derivative (see formation of $\mathbf{1 8}$ in Scheme 2). Collidine is also expected to inhibit the acid catalyzed substitution process leading to dialkylation that can take place if the medium becomes too acidic.

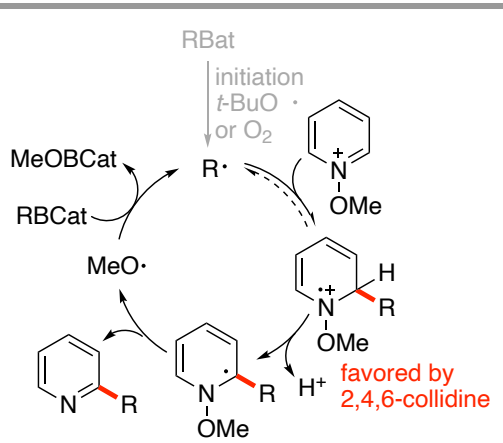

Scheme 4. Propose chain mechanism for the alkylation of $N$-methoxypyridinium salts.

The formation of MeO-Bcat was confirmed by analysis of the crude product before purification. Although 1.5 equivalents of $t$-BuOBcat are formed during the treatment of the of excess catBH with tert-butanol, the presence of nearly one equivalent of MeOBcat can be detected by ${ }^{11} \mathrm{~B}$ NMR. Indeed, the two borate esters give distinct signal at $+22.4 \mathrm{ppm}$ ( $t$-BuBcat) and +23.5 ppm (MeOBcat). ${ }^{49}$

\section{b) Reactions with alkyl iodides}

\section{Design and scope of the reaction}

In order to extend the scope of the reaction to radicals generated from alkyl iodides, the reaction of $\mathrm{N}$ methoxyquinolinium and substituted $N$-methoxypyridiums with alkyl iodides in the presence of triethylborane as a chain transfer agent was attempted (Scheme 2). Starting from $\mathbf{1 b}$, in the absence of alkyl iodides, the formation of the ethylated 
product 7 was observed in $79 \%$ isolated yield (92\% based on GC analysis). In the presence of cyclohexyl iodide (10 equiv), a mixture of the cyclohexylated product $\mathbf{2}(45 \%)$ and ethylated 7 (42\%) was obtained. The reaction with isopropyl iodide provided 21 (61\%) together with 7 (20\%). This result was expected since iodine atom transfer process between a primary alkyl radical is faster with isopropyl iodide than with cyclohexyl iodide. Reaction of the methoxyquinaldinium $1 \mathrm{f}$ with cyclohexyl iodide 10-20 equiv) and triethylborane afforded the cyclohexylated quinaldine $\mathbf{1 5}$ in $28 \%$ yield. In this case, the ethylated product was only formed in traces amount, indicating clearly that the $\mathrm{N}$-methoxyquinaldinium salt is less reactive than the corresponding lepidinium derivative towards alkyl radicals resulting in a more efficient iodine atom transfer process. The reaction was further investigated with $N$-methoxy-4phenylpyridinium $\mathbf{1 a}$ and $\mathrm{N}$-methoxy-2,6-lutidinium $\mathbf{1 i}$ and freshly distilled alkyl iodides through either slow- or portionwise addition of triethylborane. Under these conditions, the products 22-26 were obtained in moderate to good yields using 6 equivalents of the starting iodides. The reaction with cholesteryl iodide ( 3 equivalents) afforded the desired lutidine $\mathbf{2 7}$ in $\mathbf{3 7 \%}$ with an excellent level of stereocontrol. Similar yields were obtained in reactions involving the 4-chloro and 4-bromo$\mathrm{N}$-methoxypyridinium salts $\mathbf{1} \mathbf{j}$ and $\mathbf{1 k}$ with secondary and tertiary radicals (28-33). Highly electrophilic pyridinium salts such as 2,4- and 2,6-dichloro derivatives $\mathbf{1 l}$ and $\mathbf{1 m}$ afforded the corresponding products 35-37 in good yields. Among the latter, the adducts $\mathbf{3 4}$ and $\mathbf{3 7}$ are particularly attractive as two different heterocyclic structures are merged together in a single step.

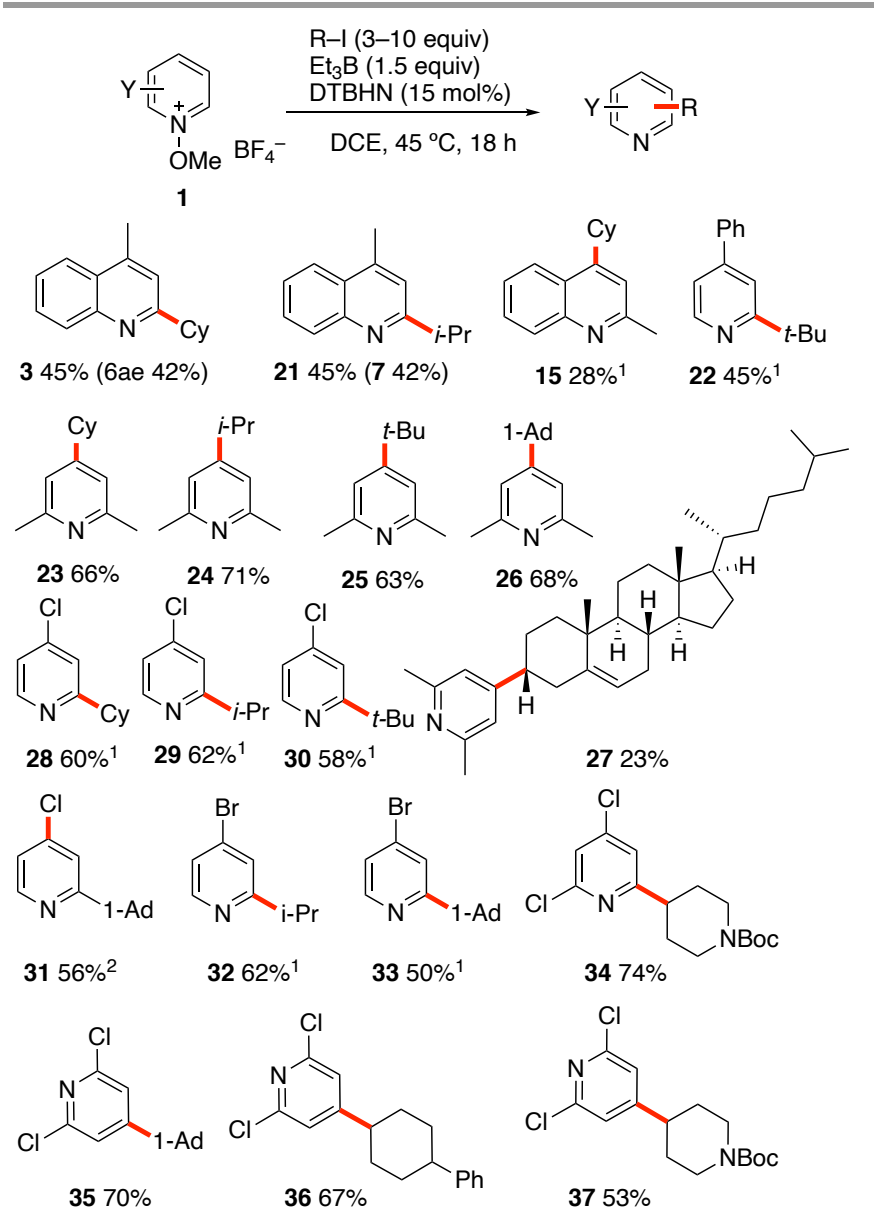

Scheme 5. Alkylation of quinolines and pyridines with alkyl iodides. 1) Using 2,4,6collidine ( 3 equiv) as a base. 2 ) Using $\mathrm{K}_{2} \mathrm{CO}_{3}$ ( 3 equiv) as a base.

\section{Kinetic study and reversibility of the radical addition}

The generation of the ethylated product $\mathbf{7}$ competes with the cyclohexylated product $\mathbf{3}$ when the $\mathrm{N}$-methoxylepidinium 1b was treated with triethylborane and cyclohexyl iodide (10 equivalents). Since the rate of iodine atom transfer between cyclohexyl iodide and a primary alkyl radical (the $n$-octyl radical) $\left(k_{\text {IAT }}=5.4 \pm 0.9 \times 10^{5} \mathrm{M}^{-1} \mathrm{~s}^{-1} \text { at } 50^{\circ} \mathrm{C}\right)^{50}$ has been reported, it is possible to estimate the rate of addition $k_{\text {add }}$ to $N$ methoxylepidinium by running a competition experiment. For this purpose, mixture of $\mathbf{1} \mathbf{b}$ and various amounts of cyclohexyl iodide were treated with $\mathrm{Et}_{3} \mathrm{~B}$ under DTBHN initiation. The reaction was stopped at low conversion to ensure quasi steady state conditions. Plotting the ratio of $\mathbf{3} / \mathbf{7}$ relative to $\mathbf{1 b} /$ Cyl gave a straight line whose slope give a $k_{\text {rel }}=k_{I A T} / k_{\text {add }}$. Results are summarized in Figure 1. From this study, a rate constant for the radical addition to $\mathrm{N}$-methoxylepidinium 1 b of $1.7 \pm 1 \times 10^{7} \mathrm{M}^{-}$ ${ }^{1} \mathrm{~s}^{-1}\left(50^{\circ} \mathrm{C}\right)$ was obtained. This is more than one order of magnitude larger than the rate constant measured for primary alkyl radical addition to protonated lepidine $\left(k_{\text {add }}=2.5 \times 10^{5} \mathrm{M}^{-}\right.$ $\left.{ }^{1} \mathrm{~s}^{-1}\left(25^{\circ} \mathrm{C}\right)\right)^{51}$ confirming the remarkable reactivity of $\mathrm{N}$ methoxypyridinium salts towards radicals. 


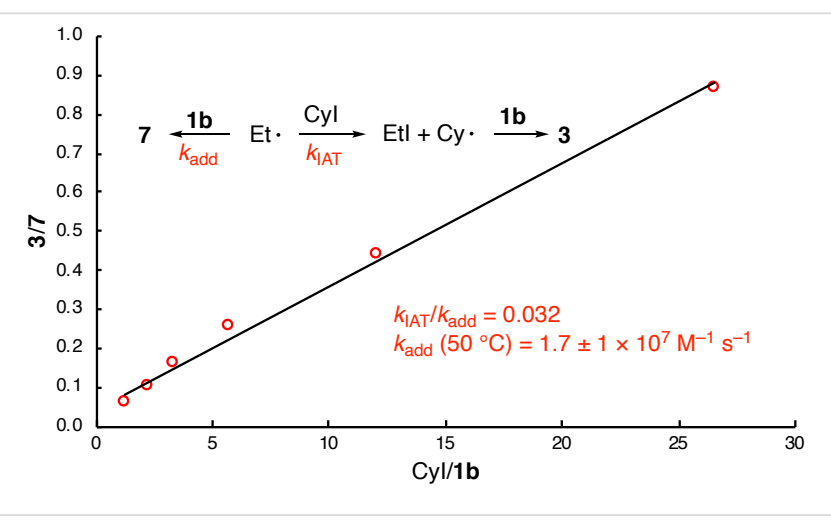

Figure 1. Estimation of the rate constant $k_{\text {add }}$ for the addition of the ethyl radical to $1 \mathrm{~b}$ at $50^{\circ} \mathrm{C}$.

The reaction of 2-chloro- $N$-methoxypyridinium salt 1 n with isopropyl iodide afforded $\mathbf{3 8}$ in $36 \%$ as a nearly $1: 1$ mixture of 4and 6-isopropyl regioisomers (Scheme 6A). On the other hand, the same reaction with 1-iodoadamantane afforded 39 in $58 \%$ as a 4-Ad/6-Ad 94:6 mixture. The impressive difference of regioselectivity between a secondary and a tertiary radical may not strictly reflect the different rates of addition but it may also be a consequence of the possible reversibility of the reaction. By using $\mathrm{K}_{2} \mathrm{CO}_{3}$, a less bulky and more reactive base, a similar yield was obtained for $\mathbf{3 8}$ but the formation of the 2-isopropyl6 -chloropyridine became the major process. This influence on the regioselectivity is attributed to a faster deprotonation of the intermediate radical cation that favor the 2-isopropyl kinetic addition product. Another indication of reversibility was observed when the alkylation of $N$-methoxy-2,6dimethylpyridine $1 \mathbf{i}$ was run with an equimolar excess of a tertbutyl and adamantyl iodide and isopropyl iodide (Scheme 6B). In both cases, the major product was the 4-isopropylpyridine $\mathbf{2 4}$ despite the fact that iodine atom abstraction involving tertbutyl iodide $\left(\mathrm{K}_{\mathrm{IAT}}=3 \times 10^{6} \mathrm{M}^{-1} \mathrm{~S}^{-1} \text { at } 50 \stackrel{\circ}{ }\right)^{50}$ and presumably also adamantyl iodide is faster than the one involving isopropyl iodide $\left(5.6 \times 10^{5} \mathrm{M}^{-1} \mathrm{~S}^{-1}\right.$ at $50 \mathrm{o}$ ).$^{50}$ This result is best explained by the higher reversibility of the addition of the more stable tert-butyl radical than the isopropyl radical. This could also explain the high para-selectivity observed for 39 with the adamantyl radical as well as the influence of the base on the regioselectivity of the formation of $\mathbf{3 8}$. In the case of the tertbutylation process, a possible cationic fragmentation leading eventually to the formation of the 2,6-lutidine (Scheme 6B, grey part) cannot be excluded.

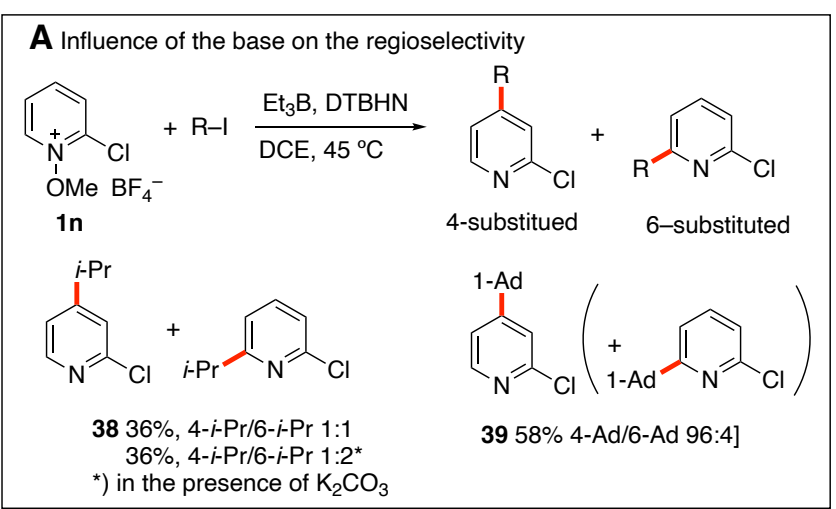

B Product ratio and rate of iodine atom transfer

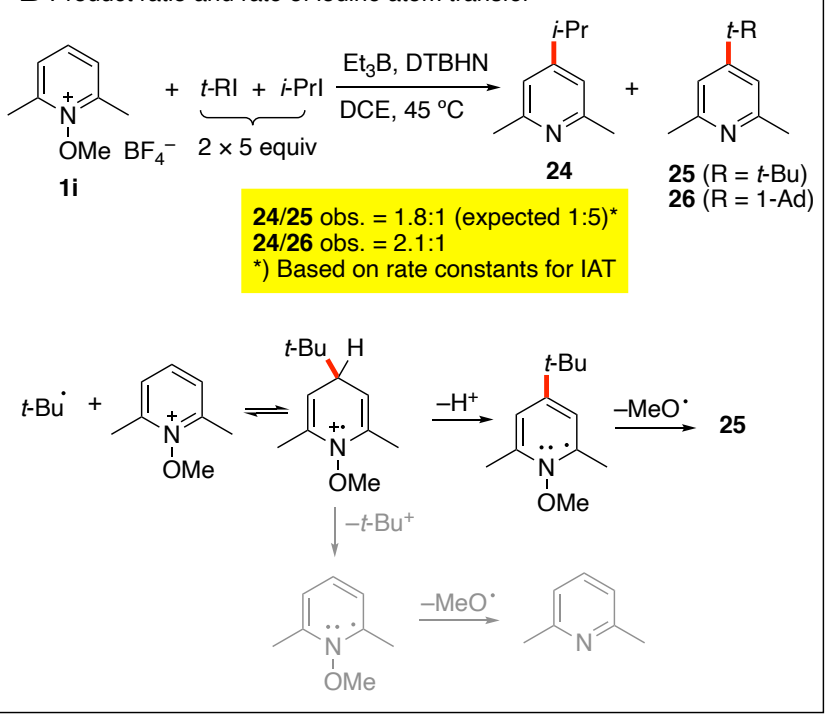

Scheme 6. Regioselectivity and possible reversibility of the radical addition.

\section{c) Reaction with xanthates}

The generation of more functionalized radicals such $\alpha$ oxygenated and $\beta$-silylated radicals from iodide radical precursors cannot be performed due to the instability of the required iodides. This issue could be efficiently circumvented by using the more stable xanthate radical precursors. ${ }^{52-54}$ The xanthates 40a-d were prepared by adding ethyl 2((ethoxycarbonothioyl)thio)acetate to 1-nonene, allyltrimethylsilane, vinyl acetate, and vinyl butyl ether. Reaction of these three radical precursors with different $\mathrm{N}$ methoxypyridium salts $\mathbf{1} \mathbf{i}-\mathbf{k}$ have been examined and results are reported in Scheme 7 . The products $\mathbf{4 1 - 4 6}$ were isolated in moderate to excellent yields and the reaction tolerates the presence of a trimethylsilyl group at position 2 as well as 1acetoxy and 1-butoxy groups. 
<smiles>CCCCC(CCCC)C(CCC(=O)OCC)c1cc(C)nc(C)c1</smiles>

$4157 \%$<smiles>CCOC(=O)CCC(OCC)c1cc(Cl)ccn1</smiles>

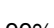

$\mathrm{Et}_{3} \mathrm{~B}$ (0.5 equiv) DTBHN (0.15 equiv) collidine $\mathrm{DCE}, 50^{\circ} \mathrm{C}, 12 \mathrm{~h}$ 40 (3 equiv)<smiles>CCOC(=O)CCC(CCC(=O)OCC)c1cc(C)nc(C)c1</smiles>
$4241 \%$<smiles>CCOC(=O)CCC(OCC)c1cc(Br)ccn1</smiles><smiles>CCOC(=O)CCC(OCC)c1cc(Cl)ccn1</smiles>

$4649 \%$

Scheme 7. Alkylation of pyridines with functionalized xanthates.

\section{d) One-pot three-component alkylation of $\mathbf{N}$ - methoxypyridinium salts}

The reaction involving iodides and xanthates described above, open the possibility to develop a three-component coupling process involving a radical precursor, an alkene, and a $\mathrm{N}$ methoxypyridinium salt. This approach is expected to complement the related photoredox catalyzed approaches involving $\mathrm{N}$-methoxypyridinium salts, ${ }^{31-33}$ lepidinium and quinaldinium trifluoroacetate, 55 as well as quinoxalin-2(1H)ones. ${ }^{56}$ Products presented in Scheme 7 results from such a two-step carbopyridinylation reaction. Indeed, the xanthates 40a-d are prepared by radical mediated xanthate transfer addition to the corresponding alkenes. ${ }^{52-54}$ Since electrophilic radicals are expected to react inefficiently with the $N$ methoxypyridinium salts $\mathbf{1}$, a one-pot was expected to be feasible. Indeed, the three component coupling process involving $N$-methoxypyridinium salts $\mathbf{1}$, electron rich alkenes $\mathbf{4 7}$ and ethyl $\alpha$-iodo- $\alpha$-((ethoxycarbonothioyl)thio)acetate in the presence of $\mathrm{Et}_{3} \mathrm{~B}$ and DTBHN as an initiator afforded the desired three component coupling products in moderate yields (Scheme 8). 1-Nonene 47a reacted well with the iodoacetate and the $N$-methoxypyridinium salt $\mathbf{1 b}, \mathbf{1} \mathbf{j}$ and $\mathbf{1 d}$ led to the formation of $\mathbf{4 8 - 5 0}$ in $\mathbf{2 8 - 5 2 \%}$ yield. Interestingly, even the non-protected allyl alcohol $47 \mathrm{~b}$ could be used in this process giving the $\mathbf{5 1}$ in $\mathbf{2 6 \%}$ yield. For 2,2-dissubstitued alkenes such 1phenyl-1-methylenecyclohexene 47c, best results for the formation of $\mathbf{5 2}$ were obtained with the xanthate radical precursor. Similar results were obtained with $n$ vinylpyrrolidinone $\mathbf{4 7 d}$ and 2 -acetoxypropene $\mathbf{4 7 e}$. In these last examples, the one-pot three component approach is the only way to perform the transformation since isolation of the intermediate tertiary xanthate proved to be impossible. Moderate yields for the formation of 53-55 were obtained when the reactions were performed under these conditions.

$$
\begin{aligned}
& \text { } \\
& 1 \quad 47 \text { (4 equiv) } X=I, S C \text { (S)OEt }
\end{aligned}
$$
(4.5 equiv)<smiles>CCCC(CCC(=O)OCC)c1cc(C)c2ccccc2n1</smiles><smiles>CCOC(=O)CCC(CC)c1cc(Cl)ccn1</smiles>
$4852 \%(X=I)$ $4928 \%(X=1)$<smiles>CCCC(CCC(=O)OCC)c1nc2ccccc2c2ccccc12</smiles>
$5048 \%(X=1)$<smiles>CCOC(=O)CCC1(c2cc(Cl)nc(Cl)c2)CCC(c2ccccc2)CC1</smiles>

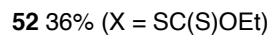<smiles>CCOC(=O)CCC(C)(OCC)c1cc(C)c2ccccc2n1</smiles>

$5430 \%(X=S C(S) O E t)$

Scheme 8. Carbopyridinylation of alkenes (three component coupling process)

\section{Conclusion}

An efficient and experimentally simple method for monoalkylation of pyridine derivatives and related compounds has been developed. The transformation is achieved by reaction of the $\mathrm{N}$-methoxypyridinium salts, easily prepared by alkylation of the $\mathrm{N}$-oxides with trimethyloxonium tetrafluoroborate (Meerwein salt). The very high selectivity observed for the formation of monoalkylated products is best explain by the exceptional reactivity of the $\mathrm{N}$-methoxypyridinium salts towards radicals. Indeed, these pyridine salts were found to react faster with radicals than the corresponding protonated pyridines. The generality of the process is demonstrated by using radicals generated either from alkenes via a hydroboration process, from alkyl iodides and from xanthates. All these reactions rely on an efficient chain reaction involving the fragmentation of a weak $\mathrm{N}$-OMe bond leading to rearomatization and generation of methoxyl radical that sustain the chain process by reaction with an organoboron species. Based on strong favorable polar effects, a three-component coupling process leading to the carbopyridinylation of electron rich alkenes could be performed. This work is expected to find applications natural product synthesis and this aspect of the chemistry is currently further investigated. 


\section{Author Contributions}

PR secured funding for the project and wrote the initial research proposal. P.R., S.R. and C.M. conceptualized the work and interpretated the results. S.R., C.M. and K.M. conceived and performed experiments. S.R. wrote the initial draft, P.R. and C.R. prepared the final version and all the authors discussed the results and commented on the manuscript.

\section{Conflicts of interest}

There are no conflicts to declare.

\section{Acknowledgements}

The Swiss National Science Foundation (Project 200020_172621) is gratefully acknowledged for financial support.

\section{References}

1 N. Kerru, L. Gummidi, S. Maddila, K. K. Gangu and S. B. Jonnalagadda, Molecules, 2020, 25, 1909.

2 E. Vitaku, D. T. Smith and J. T. Njardarson, J. Med. Chem., 2014, 57, 10257-10274.

3 F. O'Hara, D. G. Blackmond and P. S. Baran, J. Am. Chem. Soc., 2013, 135, 12122-12134.

4 F. Minisci, in Synthetic and Mechanistic Organic Chemistry, eds. F. Minisci, J. B. Hendrickson and C. Wentrup, Springer, Berlin, Heidelberg, 1976, pp. 1-48.

5 W. R. Bowman and J. M. D. Storey, Chem. Soc. Rev., 2007, 36, 1803-1822.

6 F. Minisci, R. Bernardi, F. Bertini, R. Galli and M. Perchinummo, Tetrahedron, 1971, 27, 3575-3579.

7 M. A. J. Duncton, MedChemComm, 2011, 2, 1135-1161.

8 T. Caronna, G. Fronza, F. Minisci, O. Porta and G. P. Gardini, J. Chem. Soc. Perkin Trans. 2, 1972, 1477-1481.

9 G. A. Molander, V. Colombel and V. A. Braz, Org. Lett., 2011, 13, 1852-1855.

10 M. Presset, N. Fleury-Bregeot, D. Oehlrich, F. Rombouts and G. A. Molander, J Org Chem, 2013, 78, 4615-9.

11 G.-X. Li, C. A. Morales-Rivera, Y. Wang, F. Gao, G. He, P. Liu and G. Chen, Chem. Sci., 2016, 7, 6407-6412.

12 I. B. Seiple, S. Su, R. A. Rodriguez, R. Gianatassio, Y. Fujiwara, A. L. Sobel and P. S. Baran, J. Am. Chem. Soc., 2010, 132, 13194-13196.

13 J. Jin and D. W. C. MacMillan, Nature, 2015, 525, 87-90.

14 Y. Fujiwara, J. A. Dixon, F. O'Hara, E. D. Funder, D. D. Dixon, R. A. Rodriguez, R. D. Baxter, B. Herlé, N. Sach, M. R. Collins, Y. Ishihara and P. S. Baran, Nature, 2012, 492, 95-99.

15 Y. Fujiwara, J. A. Dixon, R. A. Rodriguez, R. D. Baxter, D. D. Dixon, M. R. Collins, D. G. Blackmond and P. S. Baran, J. Am. Chem. Soc., 2012, 134, 1494-1497.

16 W.-M. Cheng, R. Shang, M.-C. Fu and Y. Fu, Chem. - Eur. J., 23, 2537-2541.

17 G. Deng and C.-J. Li, Org. Lett., 2009, 11, 1171-1174.

18 L. Fang, L. Chen, J. Yu and L. Wang, Eur. J. Org. Chem., 2015, 1910-1914.

19 A. P. Antonchick and L. Burgmann, Angew. Chem. Int. Ed., 2013, 52, 3267-3271.

20 X. Li, H.-Y. Wang and Z.-J. Shi, New J. Chem., 2013, 37, 17041706.

21 G. Deng, K. Ueda, S. Yanagisawa, K. Itami and C.-J. Li, Chem. Eur. J., 15, 333-337.
22 W. Sun, Z. Xie, J. Liu and L. Wang, Org. Biomol. Chem., 2015, 13, 4596-4604.

23 R. B. Katz, J. Mistry and M. B. Mitchell, Synth. Commun., 1989, 19, 317-325.

24 G. A. Russell, L. Wang and C.-F. Yao, J. Org. Chem., 1995, 60, 5390-5395.

25 M. A. AmrollahiBiyouki, R. A. J.Smith, J. J. Bedford and J. P. Leader, Synth. Commun., 1998, 28, 3817-3825.

26 X. Ma and S. B. Herzon, J. Am. Chem. Soc., 2016, 138, 87188721.

27 X. Ma, H. Dang, J. A. Rose, P. Rablen and S. B. Herzon, J. Am. Chem. Soc., 2017, 139, 5998-6007.

28 I. Kim, G. Kang, K. Lee, B. Park, D. Kang, H. Jung, Y.-T. He, M.H. Baik and S. Hong, J. Am. Chem. Soc., 2019, 141, 9239-9248.

29 S. Jung, H. Lee, Y. Moon, H.-Y. Jung and S. Hong, ACS Catal., 2019, 9, 9891-9896.

30 L. Shen, X. Gao, N. Luan, Z. Liu, J. Li, D. Zou, Y. Wu and Y. Wu, Org. Biomol. Chem., 2020, 18, 1738-1742.

31 Y.-T. He, J. Won, J. Kim, B. Park, T. Kim, M.-H. Baik and S. Hong, Org. Chem. Front., 2018, 5, 2595-2603.

32 J. Q. Buquoi, J. M. Lear, X. Gu and D. A. Nagib, ACS Catal., 2019, 9, 5330-5335.

33 J. M. Lear, J. Q. Buquoi, X. Gu, K. Pan, D. N. Mustafa and D. A. Nagib, Chem. Commun. Camb. U. K., 2019, 55, 8820-8823.

34 A.-P. Schaffner and P. Renaud, Eur. J. Org. Chem., 2004, 2004, 2291-2298.

35 M. R. Sabol, J. M. Owen and W. R. Erickson, Synth. Commun., 2000, 30, 427-432.

36 C. E. Garrett and G. C. Fu, J. Org. Chem., 1996, 61, 3224-3225.

37 J. Boukouvalas, S. Cren and P. Renaud, in Encyclopedia of Reagents for Organic Synthesis, American Cancer Society, 2007.

38 A.-P. Schaffner and P. Renaud, Angew. Chem. Int. Ed., 2003, 42, 2658-2660.

39 D. Griller and K. U. Ingold, Acc. Chem. Res., 1980, 13, 317-323.

40 V. W. Bowry and K. U. Ingold, J. Am. Chem. Soc., 1992, 114, 4992-4996.

41 C. Carra and J. C. Scaiano, Eur. J. Org. Chem., 2008, 44544459.

42 G. Villa, G. Povie and P. Renaud, J. Am. Chem. Soc., 2011, 133, 5913-5920.

43 E. D. Lorance, W. H. Kramer and I. R. Gould, J. Am. Chem. Soc., 2004, 126, 14071-14078.

44 D. Shukla, W. G. Ahearn and S. Farid, J. Org. Chem., 2005, 70, 6809-6819.

45 E. D. Lorance, K. Hendrickson and I. R. Gould, J. Org. Chem., 2005, 70, 2014-2020.

46 E. D. Lorance and I. R. Gould, J. Phys. Chem. A, 2005, 109, 2912-2919.

47 R. Ueno, Y. Ikeda and E. Shirakawa, Eur. J. Org. Chem., 2017, 4188-4193.

48 R. Ueno and E. Shirakawa, Org. Biomol. Chem., 2014, 12, 7469-7473.

49 G. Povie, G. Villa, L. Ford, D. Pozzi, C. H. Schiesser and P. Renaud, Chem. Commun., 2010, 46, 803-805.

50 M. Newcomb, R. M. Sanchez and J. Kaplan, J. Am. Chem. Soc., 1987, 109, 1195-1199.

51 A. Citterio, F. Minisci, O. Porta and G. Sesana, J. Am. Chem. Soc., 1977, 99, 7960-7968.

52 S. Z. Zard, in Radicals in Organic Synthesis, eds. P. Renaud and Sibi, Wiley-VCH, 2008, vol. 1, pp. 90-108.

53 S. W. McCombie, B. Quiclet-Sire and S. Z. Zard, Tetrahedron, 2018, 74, 4969-4979.

54 S. Z. Zard, Helv. Chim. Acta, 2019, 102, e1900134.

55 T. McCallum and L. Barriault, Chem. Sci., 2016, 7, 4754-4758.

56 D. Zheng and A. Studer, Org. Lett., 2019, 21, 325-329. 